\title{
Incorporating Water Demand Management into a Cooperative Water Allocation Framework
}

\author{
Yi Xiao \\ Department of Systems Design Engineering, University of Waterloo, Waterloo, Ontario, Canada N2L 3G1 \\ E-mail:yi.xiao@uwaterloo.ca \\ Keith W. Hipel (Corresponding Author) \\ Department of Systems Design Engineering, University of Waterloo, Waterloo, Ontario, Canada N2L 3G1 \\ Centre for International Governance Innovation, Waterloo, Ontario, Canada N2L 6C2 \\ E-mail: kwhipel@uwaterloo.ca \\ Liping Fang \\ Department of Mechanical and Industrial Engineering, Ryerson University, Toronto, Ontario, Canada M5B \\ $2 \mathrm{~K} 3$ \\ E-mail: lfang@ryerson.ca
}

\begin{abstract}
The impact of a water demand management plan on a water system and its users is investigated within a comprehensive cooperative water allocation framework. In particular, a demand management plan is incorporated into a two-step multi-period fair water allocation model. A modified cooperative game is designed for the sharing of additional net benefits under the scenario having water demand management. The results indicate that cooperation among water users can yield more net benefits, and a water demand management plan is able to lead to a further increase of the aggregated net benefits by means of water transfers from less productive users to more productive ones. By utilizing the modified cooperative game, fair sharing of additional net benefits ensures that every water user can expect to receive more net benefits and thereby water users are motivated by incentives to implement a water demand management plan which in turn improves water use efficiency. The results demonstrate that the demand management plan can be of great assistance in some arid and semi-arid regions.
\end{abstract}

Keywords Water Allocation; Water Demand Manegement; Cooperative Game; Water Efficiency; Water Conservation; Net Benefits 


\section{Introduction}

Challenged by the growing demand for water and limited supply of water, the question of how to allocate water resources among competing demand uses during shortage periods has become a critical issue and has attracted much attention from water managers and researchers globally (Speed et al. 2013). Numerous water conflicts have been caused by the imbalance between water supply and demand (Gleick and Heberger 2014). Various practical efforts have been made by water managers such as the expanding of construction of water infrastructures over the past century in order to increase water supply. These efforts have effectively alleviated water stresses facing humanity, and have provided massive benefits in terms of greater economic returns and fewer water-related disasters. However, the construction of infrastructures often brings unanticipated adverse effects such as migration relocation, reduced runoff, and species extinction (Gleick 2003a). Along with the dramatically growing water demand, increasing supply to meet the future demand is no longer a cost-effective way towards a sustainable future; more proactive water management techniques are required.

Water resources allocation problems are essentially concerned with how to distribute limited water resources among competing activities to achieve maximum social welfare. As a result, optimization methods are frequently utilized in terms of modelling techniques to find an optimal water allocation scheme. Many optimization techniques have been proposed, including linear programming (Takama et al. 1981; Jacobs and Vogel 1998; Kucukmehmetoglu and Guldmann 2010), non-linear programming (Cai et al. 2003; Kilic and Anac 2010; Yang et al. 2011), dynamic programming (Alaya et al. 2003; Luo et al. 2007), genetic algorithms (Ahmed and Sarma 2005; Nicklow et al. 2010), and any combination of these techniques (Cai et al. 2001; Huang et al. 2002; Li et al. 2009).

One of the deficiencies of optimization techniques is that they assume every stakeholder is acting voluntarily to achieve optimal system-wide performance. However, the optimal system-wide outcome does not necessarily mean the best outcome for every individual stakeholder. It is important to provide motivation to every stakeholder, such as obtaining greater (or, at least, not any less) economic benefits, in order to achieve the best system performance.

Because water allocation is a problem involving multiple stakeholders, in which each stakeholder has different interests, conflicts usually arise in water allocation. Accordingly, game theory is a powerful tool that can be utilized to investigate the behavior of stakeholders in water management problems, and many studies have been done in this domain (Madani 2010; Madani and Hipel 2011). Cooperative game theory, as a major branch of game theory, studies how the gains of cooperation can be shared within a coalition, thus making it a powerful technique in the water allocation domain. Cooperative game theory has been successfully applied to many areas within water management such as cost allocation of water projects (Young et al. 1982; Sechi et al. 2013) and waste load allocation (Kilgour et al. 1988; Okada and Mikami 1992), but possesses limited application to water allocation. To fill in the gap, a comprehensive water allocation framework based on cooperative game theory was proposed (Wang et al. 2003, 2008). In this structure, water allocation is carried out in two steps: initial allocation based on existing water rights systems or agreements, and cooperative reallocation involving water transfer and benefits sharing among water users. More details about the framework are discussed in Section 3.

Since the initial allocation is calculated according to several principles of fairness and the reallocation is obtained by solution concepts from cooperative game theory such as the core and Shapley value, the framework solves water allocation problems in a fair way. In fact, it can provide a reasonable solution during periods of water shortage. However, as mentioned above, the future demand cannot be satisfied if the demand continues its exponential growth. Fair water allocation alone is not sufficient for future scenarios; accordingly, the focus of water management needs to shift to demand side management, and water users should be encouraged to use water more efficiently and productively. In this paper, a water demand management plan is incorporated into 
the cooperative water allocation framework, and its associated impacts are assessed. This research constitutes a significant expansion of previous work published by the authors in a conference paper (Xiao et al. 2015). The novelty of this paper is the incorporation of the idea of water demand management into a water allocation procedure, and the fair sharing of additional net benefits among users through cooperative game theoretic approaches. Water users are motivated by incentives to implement water demand management which in turn improves water use efficiency, thereby moving formal decision making towards sustainable water resources development.

\section{Water Demand Management}

The demand for water is expected to grow sharply in the near future due to the burgeoning global population, economic development, and an increasing awareness of environmental conservation, while the availability of water supply will remain constant or even be reduced because of climate change impacts and water pollution. During the past few decades, water management has witnessed a gradual shift from water supply management towards water demand management. It should be noted that water demand management should be considered as an important complement rather than a replacement to water supply management, because new water supply infrastructures will continue to be constructed, and there are ongoing research on desalination and recycling wastewater as new sources of water supply (Sahin et al. 2015; Ziolkowska 2015). Moreover, water users are encouraged to improve their water use efficiency, but how to motivate users to use water more efficiently is still one of the biggest challenges facing water policy makers and managers.

Focusing on influencing water consumption by water users and promoting water use efficiency, water demand management is widely considered as a promising path towards the sustainable development of water resources. Measures that can be taken include water-saving technologies, economic instruments, educational programs, and administrative measures (Kindler 2010). This approach can be of great assistance in arid and semi-arid areas and extreme conditions such as droughts, and it will continue to play an increasingly important role in water management in the future.

Successful applications of water demand management have been reported in some nations (Tate 1989; Kampragou et al. 2011; Tortajada and Joshi 2013), and many studies have been carried out on the issue (Savenije and van der Zaag 2002; Brooks 2006; Araral and Wang 2013). However, most studies and applications focus on urban water demand and are based on economic instruments such as water pricing and water tariffs, whereas there are few studies at the basin level. A basin is a unit that is widely used in water allocation problems. Therefore, it is important and interesting to investigate the impacts of water demand management at the basin level.

Water has traditionally been viewed as an indispensable resource for activities like agricultural production, economic development, and ecosystem maintenance. These activities compete for limited water resources. However, the real purpose of water use is to produce products and services to satisfy people's needs. As explained by Gleick et al. (2011), "people want to satisfy demands for goods and services, such as food, fiber, waste disposal, they may not care how much water is used - or even whether water is used at all - as long as these goods and services are produced in convenient, cost-effective, and socially acceptable ways". A particular example is that about 100 to 200 tons of water was needed to produce a ton of steel in the 1920s, while less than four tons of water is required for each ton of steel produced nowadays (Gleick 2003b).

The basic idea of a water demand management plan is that every water user has the potential to improve its water use efficiency, such that certain tasks can be carried out with less water. For instance, less water is needed to irrigate a farm with a drip system or sprinkler technology compared to flood irrigation. Since water use can be reduced while the same level of outputs be maintained, the water demand of each user or user group can be adjusted by a different factor according to its capacities for adjustment, as well as the socioeconomic consequences arising from the changes. 
An example of a water demand management plan is reducing the demand of water for agricultural and industrial uses by $25 \%$ and $10 \%$, respectively, while maintaining the water demand for hydropower, environmental, and domestic uses at the original levels. It is reported that almost $70 \%$ of the extracted freshwater is used for irrigation purposes globally (FAO 2013), and the number can be as high as $80 \%$ in some regions such as California (Christian-Smith et al. 2012). Irrigation is generally considered as the largest water consumer in a basin. Moreover, irrigation often has the highest priority in regions having a prior rights system based on the doctrine of "first in time, first in rights", because farmers normally appeared before other water consumers did. Meanwhile, irrigation water use efficiency is generally low, especially when a flood irrigation method is still widely utilized. The conserved water from agricultural uses can be reallocated to meeting urban demands or environmental purposes. A case study in California indicated that $13 \%$ of agricultural water consumption is able to be conserved for reallocation to other uses even if its irrigation water use efficiency is already above $73 \%$ (Christian-Smith et al. 2012). One can assume that more water can be conserved in agriculture in regions having low water use efficiency.

In this paper, a water demand management plan is incorporated into a cooperative water allocation model to investigate its impact on water users. Various levels of reduction will be assessed. One of the advantages of this plan is that the performance of the system is expected to be better in terms of greater economic benefits for every water user; thus, it can provide positive incentives for water users to implement a demand management plan. The main reasons are: (1) water use efficiency improvement, (2) water transfer from low productive users to high productive users, and (3) cooperation among water users.

It should be noted that the means of achieving these levels of reduction of water use is beyond the scope of this paper, because there are numerous ways to improve water use efficiency and each way has a different impact on the decrease in water use. Furthermore, the cost of adopting different measures can be diverse. For example, the impact and the cost of adopting new drip irrigation technology and that of adopting an advanced irrigation schedule may be quite different. Moreover, the impact and the cost of a particular measure may vary from basin to basin.

\section{Cooperative Water Allocation with Water Demand Management}

Conflicts among water users always exist in water resources allocation because each water user has its own interests, and these interests normally conflict with one another. Optimization approaches alone may not be able to provide an adequate solution to the conflict. The combination of optimization techniques and game theory could provide a proper path for better conflict resolution in assisting water policy makers and water managers. In this section, a comprehensive water allocation framework at the basin level called the Cooperative Water Allocation Model (CWAM), proposed by Wang et al. (2008), will be described and then the water demand management plan will be incorporated into the CWAM.

The objective of the CWAM is to allocate limited water resources in an equitable, efficient, and environmentally sustainable manner. It involves two main steps: initial water allocation using priority-based or lexicographic techniques, and fair reallocation of net benefits (represented in monetary terms) using cooperative game theoretic approaches.

Initial water rights allocation is carried out in a basin based on its existing water rights systems or agreements. Optimization techniques are essentially utilized for initial water allocation. Based on the existing water rights systems, three multi-objective optimization methods, called the priority-based maximal multiperiod network flow (PMMNF) approach, the modified riparian water rights allocation (MRWRA) method, and the lexicographic minimax water shortage ratios (LMWSR) approach, have been designed for initial allocation. PMMNF is a very versatile method in which water users' priority ranks are the main principle for allocating water resources. In this situation, some "junior" users with low priorities may not be able to receive any water during water shortage periods. PMMNF is applicable under the prior, riparian, and public water 
rights systems, while MRWRA is a special form of PMMNF under the riparian rights system. LMWSR is designed for sharing water shortages among all users, and is applicable under the public rights system. Sequential and iterative solution algorithms to solve the three types of problems have been developed (Wang et al. 2007), and solvers in GAMS (GAMS, 2005) can be utilized to optimize these programs.

Once the initial water rights are obtained, they are considered as inputs to the Hydrologic-Economic River Basin Model (HERBM), along with other inputs such as water demand and benefit functions of all types of uses, the set of stakeholders, coalitions and ownership. The purpose of the model is to estimate the net benefits of various coalitions and search for the water allocation schemes with the maximum net benefits in a basin. The HERBM, as a core component, is formulated as:

$$
\max \left(\sum_{j} \sum_{t} N B_{j t}: \lambda \in \Omega\right)
$$

where $N B_{j t}$ represents the net benefits for demand site $j$ during period $t\left(\$ 10^{6}\right) ; \lambda$ denotes the decision variables consisting of water quantity and water quality; and $\Omega$ is the feasible solution space subject to hydrologic and economic constraints. The net benefits function for agricultural (AGR) use is represented by a quadratic function form, while the net benefits function for municipal and industrial (MI) use can be derived from a water price-demand function with constant price-elasticity and choke price.

More specifically, the function for agricultural use is formulated as:

$$
\begin{aligned}
& N B_{j t}=b_{0}(j, t)+b_{1}(j, t) Q(j, t)+b_{2}(j, t) \mathrm{Q}(j, t)^{2} \\
& +\sum_{p}\left[b_{3 p}(j, t) \mathrm{C}_{p N}(j, t)+b_{4 p}(j, t) \mathrm{C}_{p N}(j, t)^{2}+b_{5 p}(j, t) \mathrm{Q}(j, t) \mathrm{C}_{p N}(j, t)\right]-Q(j, t) w c(j, t), \\
& =b_{2}(j, t)\left[\mathrm{Q}(j, t)+\frac{b_{1}(j, t)}{2 b_{2}(j, t)}\right]^{2}-\frac{b_{1}(j, t)^{2}}{4 b_{2}(j, t)}+b_{0}(j, t) \\
& +\sum_{p}\left[b_{3 p}(j, t) \mathrm{C}_{p N}(j, t)+b_{4 p}(j, t) \mathrm{C}_{p N}(j, t)^{2}+b_{5 p}(j, t) \mathrm{Q}(j, t) \mathrm{C}_{p N}(j, t)\right]-Q(j, t) w c(j, t), \quad \forall j \in \mathrm{AGR}
\end{aligned}
$$

where

$Q(j, t)$ is the total inflow to demand site $j$ during period $t\left(10^{6} \mathrm{~m}^{3}\right)$,

$C_{p N}(j, t)$ is the concentration of pollutant $p$ in the total inflow to demand site $j$ during period $t$,

$w c(j, t)$ is the water supply cost $\left(\$ / \mathrm{m}^{3}\right)$,

$b_{0}$ to $b_{5 p}$ are coefficients derived from a sub-model, namely the Irrigation Water Planning Model (IWPM).

The price-demand function with constant price-elasticity and choke price for MI use is shown as:

$$
P(j, t)=\left\{\begin{array}{l}
P_{0}(j, t), \quad 0 \leq Q(j, t) \leq Q_{0}(j, t) \\
{[Q(j, t) / \alpha(j, t)]^{1 / \beta(j, t)}, \quad Q(j, t)>Q_{0}(j, t)}
\end{array}\right.
$$

where

$P(j, t)$ is the price of willingness to pay to retrieve water $\left(\$ / \mathrm{m}^{3}\right)$,

$P o(j, t)$ is the choke price $\left(\$ / \mathrm{m}^{3}\right)$,

$Q_{0}(j, t)$ is the choke quantity $\left(10^{6} \mathrm{~m}^{3}\right)$,

$\alpha(j, t)$ and $\beta(j, t)$ are parameters for the water price-demand function $(\alpha(j, t)>0, \beta(j, t)<0)$. 
Based on the water price-demand function, the net benefits for MI use can be derived as:

$$
\begin{aligned}
& N B_{j t}=\int_{0}^{Q(j, t)} P(j, t) d Q(j, t)-Q(j, t) w c(j, t) \\
& =\int_{Q_{0}(j, t)}^{Q(j, t)}[\mathrm{Q}(j, t) / \alpha(j, t)]^{1 / \beta(j, t)} d Q(j, t)+\mathrm{P}_{0}(j, t) \mathrm{Q}_{0}(j, t)-Q(j, t) w c(j, t) \\
& =(1 / \alpha(j, t))^{1 / \beta(j, t)} \frac{1}{1+1 / \beta(j, t)}\left[Q(j, t)^{1+1 / \beta(j, t)}-Q_{0}(j, t)^{1+1 / \beta(j, t)}\right]+\mathrm{P}_{0}(j, t) \mathrm{Q}_{0}(j, t)-Q(j, t) w c(j, t), \forall j \in M I
\end{aligned}
$$

When the net benefits for different coalitions are obtained, they serve as the input of the Cooperative Reallocation Game (CRG). In a cooperative game, let $N=\{1,2, \ldots, n\}$ be the set of stakeholders, and a group of stakeholders working cooperatively is called a coalition and is denoted by $S$. Each individual stakeholder can be considered as a coalition which contains the individual stakeholder only, while the coalition that contains all stakeholders is called the grand coalition.

The reallocation of net benefits is viewed as a cooperative game $(N, v)$, in which $N$ is the set of stakeholders and $v$ is the characteristic function on $N$. The notation $v(S)$ represents the maximum aggregated benefits produced by the members of coalition $S$ through internal cooperation, and is calculated by:

$$
v(S)=\max \left(\sum_{j} \sum_{t} N B_{j t}: j \in S, \lambda \in \Omega\right)
$$

Accordingly, the benefits of individual stakeholders and the grand coalition can be expressed as $v(\{1\}), v(\{2\})$, $\ldots, v(\{n\})$, and $v(N)$, respectively.

The benefits gained by stakeholders after the reallocation are denoted by a vector $\boldsymbol{x}=\left(x_{1}, x_{2}, \ldots, x_{n}\right)$. The vector is called an imputation or a solution to a cooperative game. The term $x_{i}-v(\{i\})$ represents the additional benefits that can be gained from participating in a coalition (also called participation value) for stakeholder $i$. The imputation must satisfy the conditions of individual rationality, group rationality, and joint efficiency (Young et al. 1982; Tisdell and Harrison 1992):

Individual rationality:

$$
x_{i} \geq v(\{i\}) \quad \forall i \in N
$$

Group rationality:

$$
\sum_{i \in S} x_{i} \geq v(S) \quad|S| \geq 2
$$

Joint efficiency:

$$
\sum_{i \in N} x_{i}=v(N)
$$

Various solution concepts such as core-based (nucleolus and its variations) (Young et al. 1982; Lejano and Davos 1995; Owen 1995) and non-core-based (Shapley value) (Shapley 1953) concepts are utilized for solving the cooperative game in the CWAM (Wang et al. 2003). Since the computational complexity of solving a cooperative game can be exponentially high with an increase of stakeholder numbers, simplification is necessary to reduce the computational load to a reasonable level; thus, it is useful to classify some individual stakeholders into stakeholder groups based on their types (Wang et al. 2008). 
The water allocation schemes and benefits sharing solutions generated by these solution concepts can be used to facilitate better water allocation decision-making. However, the framework does not provide a mechanism to encourage water users to improve their water use efficiency and conserve water resources. Facing the expanding gap between water supply and demand, more efforts on the demand side need to be made. Therefore, a demand management plan is incorporated into the CWAM.

When a demand management plan is implemented, it may have different impacts on different users. For example, the user who reduces its water use may gain less benefits from the utilization of water, while the user who receives more water may produce greater benefits. As a matter of course, the aggregated benefits of the coalitions may also change accordingly. The economic impact on a water reduced user might also be positive because of the efficiency improvement. The aggregated benefits of coalitions with a water demand management plan may be represented as $\tilde{v}(\{1\}), \tilde{v}(\{2\}), \ldots, \tilde{v}(\{n\}), \tilde{v}(S)$, and $\tilde{v}(N)$. Then, a new cooperative game $(N, \tilde{v})$ is formed.

All three conditions of individual and group rationality and joint efficiency must still be satisfied for solving the new cooperative game. Moreover, it is necessary to ensure that no coalition will receive less benefits than the benefits gained from cooperative reallocation without a demand management plan; otherwise, some users may not have incentives to implement the water demand management plan. Therefore, the conditions of individual and group rationality should remain the same as equations (6) and (7), while the condition of joint efficiency is modified as:

$$
\sum_{i \in N} x_{i}=\tilde{v}(N)
$$

The core-based and non-core-based solution concepts are applied to the modified cooperative game, and new results can be obtained and be assessed. The structure of the Cooperative Water Allocation Model with a water demand management plan is shown in Fig. 1.

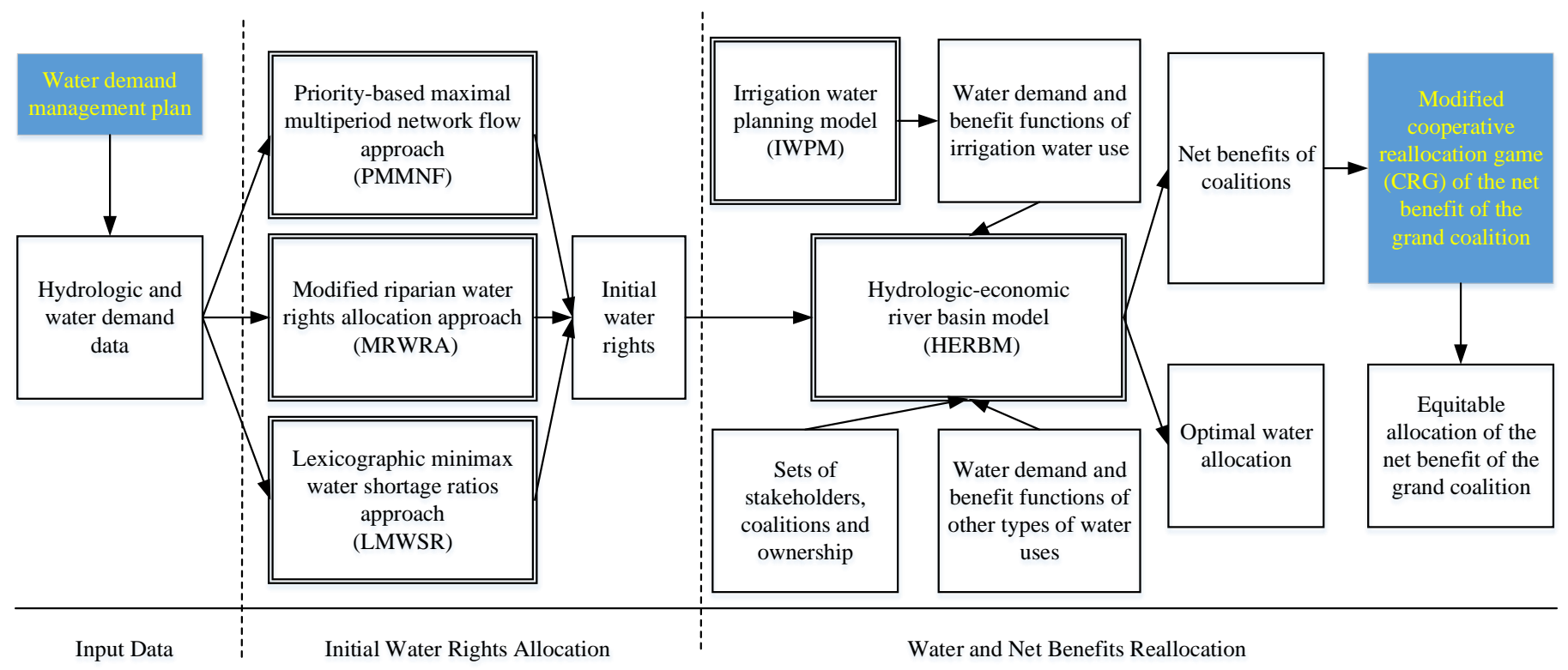

Fig. 1 Structure of the Cooperative Water Allocation Model (CWAM) with a water demand management plan (based on Hipel et al. (2013)) 


\section{Case Study}

In this section, an illustrative case is used to evaluate the impact of a water demand management plan on the economic benefits for water users. In a basin, there are typically various types of water uses, such as agricultural production, urban development, and environmental conservation, which must share the available water resources. Additionally, reservoirs are an essential part of water management operations. Without loss of generality, a hypothetical network, as depicted in Fig. 2, is designed. The network has 2 inflow (In1, In2), 1 outlet (O1), 2 reservoir (R1, R2), 2 agricultural (A1, A2), 2 domestic (D1, D2), 2 general (G1, G2), 2 industrial $(\mathrm{I} 1, \mathrm{I} 2)$, and 2 instream flow requirement $(\mathrm{S} 1, \mathrm{~S} 2)$ demand nodes. The general demand refers to municipal, excluding domestic, demand, such as water use in commercial establishments and public infrastructures. The instream flow requirement indicates the minimum instream flow needed for the sake of the safety of aquatic ecology and recreational purposes.

The water allocation problem is designed for a period of 12 months. The monthly supply and demand data are adapted from the South Saskatchewan River Basin (SSRB) case in a drought year in Wang et al. (2008). The monthly water supply consists of inflow, reservoir storage, and local adjustments from small tributaries. It should be noted that local adjustments only occurred at reservoir, junction, instream flow requirement, and outlet nodes. The initial reservoir storages are set to 163.29 million $\mathrm{m}^{3}$ and 317.06 million $\mathrm{m}^{3}$ for $\mathrm{R} 1$ and $\mathrm{R} 2$, respectively.

In this case, it is assumed that agricultural users' demand will be reduced by different percentages, such as $0 \%$ (baseline), $5 \%$, and $10 \%$, while other users maintain their original water demand. Once all the users are satisfied, then no user is willing to participate in a coalition; therefore, there will be no need to reduce agricultural users' demand further. It should also be noted that the results in this section are based on the original net benefit functions. For the case of net benefit functions with improved water use efficiency, the results will be discussed in Section 5.

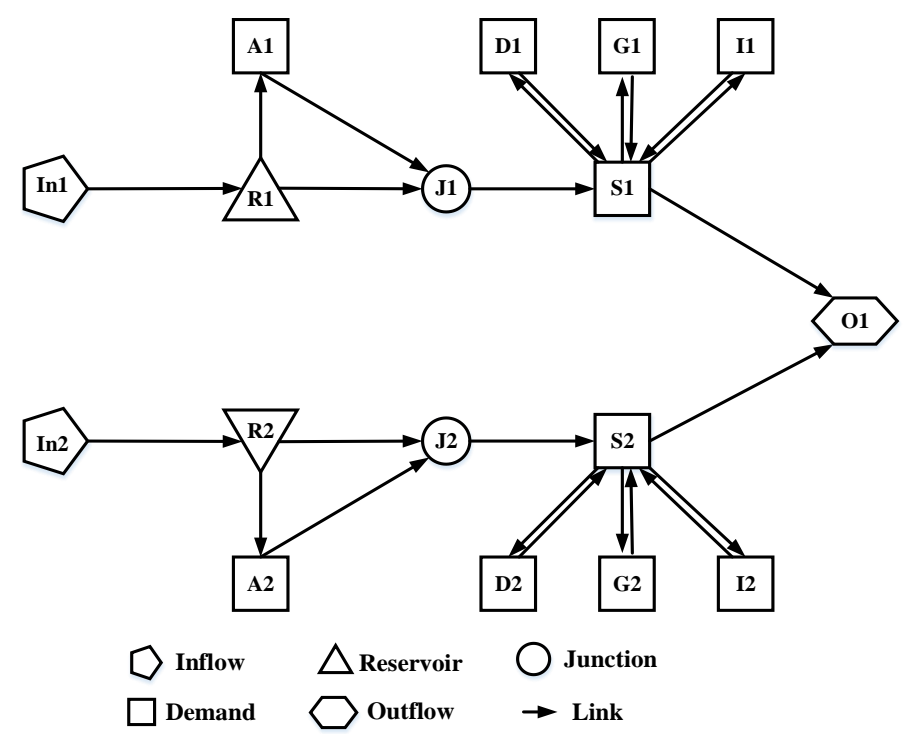

Fig. 2 The network of the illustrative case study

An uptrend can be observed for total net benefits from both initial water allocation and optimal reallocation as the level of reduction increases, as depicted in Fig. 3(a). More specifically, when the PMMNF method is utilized for initial allocation, about 1,004 million dollars can be produced from initial allocation without any reduction, and it is increased to about 1,191 million dollars from optimal reallocation, which means an extra 
187 million dollars can be produced through a grand cooperation. Along with the increased level of reduction, more net benefits can be generated, and it reaches up to about 1,284 million dollars when the level of reduction goes up to $30 \%$. The increase demonstrates that not only is cooperation among water users more beneficial, but the demand management plan also is. Moreover, this increase gives incentives for water users to implement the demand management plan, as long as the additional net benefits are shared fairly among users so that everyone can receive more benefits.

It is also observed that the gaps between the total net benefits from initial allocation and from optimal reallocation become smaller along with the increased level of reduction. The main reason for this is the conserved water from agricultural users is distributed to city users located downstream during the initial allocation. Since city users have a higher productivity than agricultural users do, as is normally the case, the overall benefits from initial allocation for the entire basin is growing rapidly, while the growth of total net benefits from optimal reallocation is more moderate. When the level of reduction reaches a certain percentage, all agricultural, domestic, general, and industrial users are fully satisfied; thus, there is no need for reallocation. This result demonstrates that water transfer from low productive users to high productive users can generate more beneficial outcomes.

A similar uptrend can be observed for total net benefits from initial allocation and from optimal reallocation when the LMWSR method is utilized for initial allocation, as depicted in Fig. 3(b). However, the increase is not as obvious as that from the PMMNF method. This is because the LMWSR method generates more evenlyspread water shortage ratios so that water is allocated in a more economically efficient manner.

The fact that cooperation is more beneficial is easy to understand. The key problems are how to fairly allocate the total net benefits among users, and how to evaluate the contribution of water users in implementing a demand management plan. For instance, the total net benefits without the plan are about 1,191 million dollars when the PMMNF method is utilized, as shown in Fig. 3(a), and this is the total net benefits of the grand coalition. Similarly, the total net benefits of the grand coalition reach about 1,243 million dollars with a $20 \%$ reduction. Therefore, the question is how to share the 1,243 million dollars among stakeholders such that every stakeholder will get no less benefits than it can get without a $20 \%$ reduction.

It is important that no stakeholder will receive less net benefits with a plan than the net benefits it can get without a plan. A summary of the net benefits gained from the modified cooperative game for stakeholders with different levels of reduction under different cooperative solution concepts is depicted in Fig. 4. The bar charts represent the total net benefits of irrigators (A1, A2), and line charts denote the total net benefits of city users (City 1, City 2). It can be seen that, compared to the baseline results, all stakeholders will receive more net benefits under the cases with water reduction. The more percentage of reduction, the more net benefits can be shared. It seems that under solution concepts such as nucleolus and weak nucleolus, more additional net benefits are shared by irrigators than by city users; while under proportional nucleolus and normalized nucleolus concepts, city users share more additional net benefits than irrigators. Under the concept of Shapley value, both irrigators and city users have a moderate growth in their net benefits. Overall, every stakeholder can expect an increase in net benefits when the demand management plan is carried out. The results also demonstrate the motivation for water users to implement the water demand management plan. 
(a)

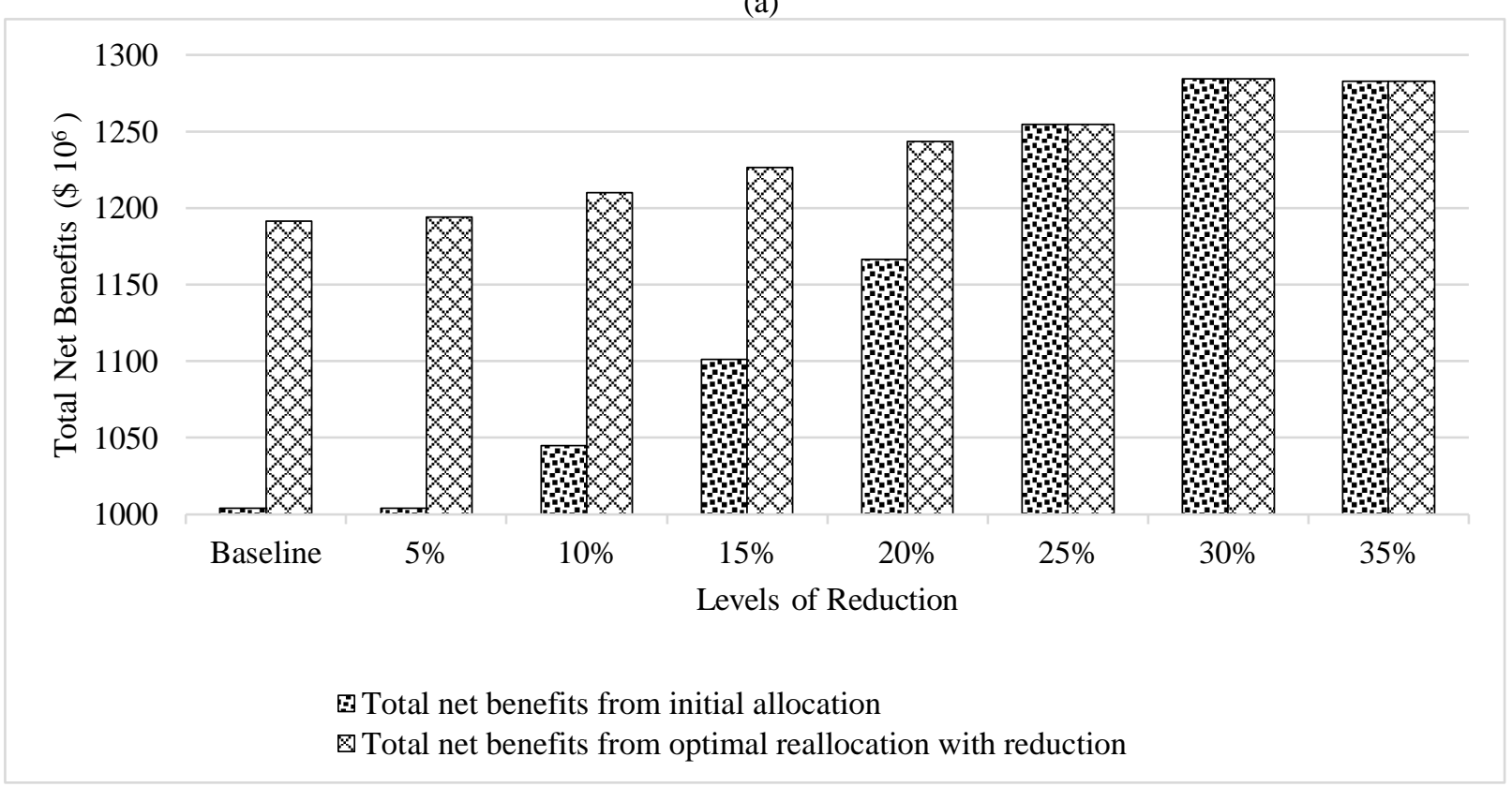

(b)

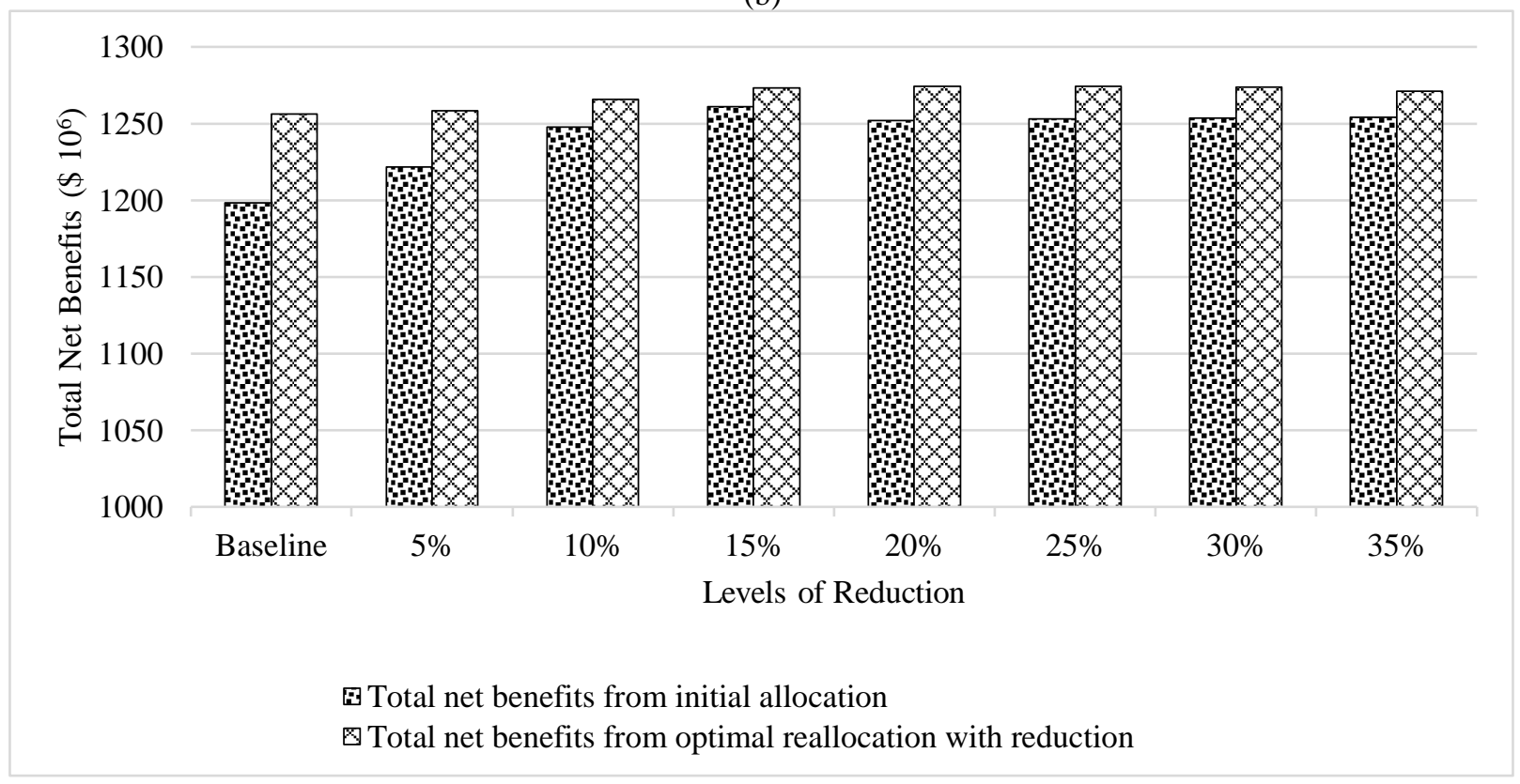

Fig. 3 (a) Total net benefits from initial water allocation and optimal reallocation for the grand coalition under different levels of reduction when initial water allocation is obtained from the PMMNF approach, and (b) total net benefits from initial water allocation and optimal reallocation for the grand coalition under different levels of reduction when initial water allocation is obtained from the LMWSR method 


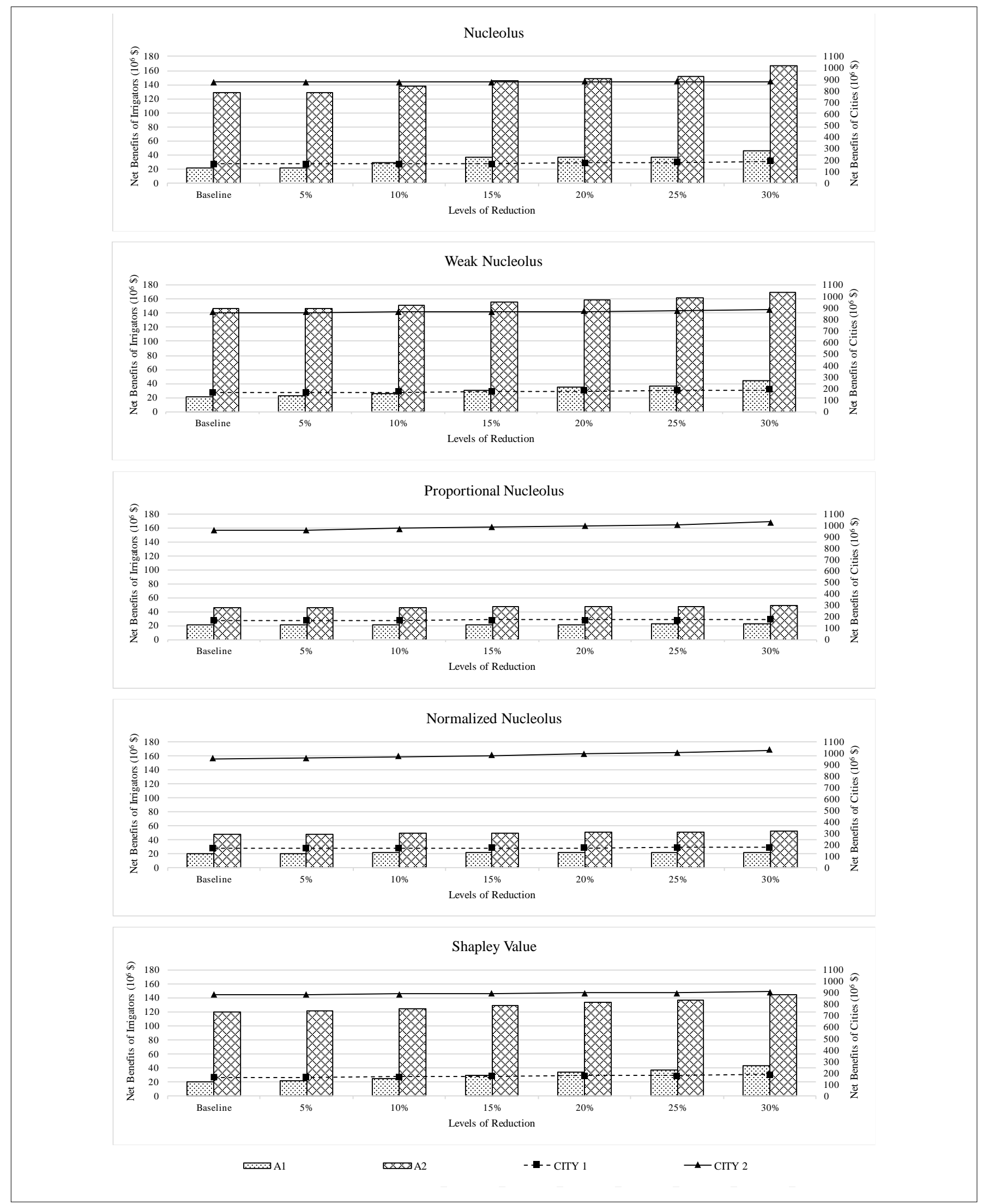

Fig. 4 Comparison between total net benefits gained from the modified cooperative game for stakeholders with different levels of reduction and baseline results under various solution concepts when initial allocation is obtained from the PMMNF approach 


\section{Discussion}

As indicated above, the reduction of water use is the consequence of water use efficiency improvement. Meanwhile, the net benefits function of each user may change along with water use efficiency improvement, and its net benefits from the utilization of water may change accordingly. In this section, the impact of net benefits functions with water use efficiency improvement on the total net benefits of each user will be further investigated.

A parameter $\rho$ is used to denote the level of water use efficiency improvement. The relation between water use efficiency improvement and level of water reduction is assumed to be linear for the sake of computation load and also because it is beyond the scope of this paper. Then, it can be incorporated into the net benefits function of each user. For agricultural users, its modified net benefits function with efficiency improvement can be formulated as:

$$
\begin{aligned}
& N B_{j t}=b_{2}(j, t)\left[\mathrm{Q}(j, t)+\frac{b_{1}(j, t)}{2 b_{2}(j, t)}(1-\rho)\right]^{2}+\left[b_{0}(j, t)-\frac{b_{1}(j, t)^{2}}{4 b_{2}(j, t)}\right](1+\rho) \\
& +\sum_{p}\left[b_{3 p}(j, t) \mathrm{C}_{p N}(j, t)+b_{4 p}(j, t) \mathrm{C}_{p N}(j, t)^{2}+b_{5 p}(j, t) \mathrm{Q}(j, t) \mathrm{C}_{p N}(j, t)\right]-Q(j, t) w c(j, t)(1+\rho), \\
& =b_{2}(j, t) \mathrm{Q}(j, t)^{2}+b_{1}(j, t) Q(j, t)(1-\rho)+b_{0}(j, t)(1+\rho)+\frac{b_{1}(j, t)^{2}}{4 b_{2}(j, t)}\left(\rho^{2}-3 \rho\right) \\
& +\sum_{p}\left[b_{3 p}(j, t) \mathrm{C}_{p N}(j, t)+b_{4 p}(j, t) \mathrm{C}_{p N}(j, t)^{2}+b_{5 p}(j, t) \mathrm{Q}(j, t) \mathrm{C}_{p N}(j, t)\right]-Q(j, t) w c(j, t)(1+\rho), \quad \forall j \in \mathrm{AGR}
\end{aligned}
$$

An example of the comparison of net benefits functions under different scenarios of efficiency improvement is depicted in Fig. 5(a). The figure shows the net benefits function with water use efficiency improvement for user A2 in May. It can be seen from the figure that more net benefits can be obtained with the same amount of water, and less water is needed to produce a certain amount of net benefits.

Similarly, when the parameter $\rho$ is taken into consideration for MI users, the modified water price-demand function can be formulated as:

$$
\tilde{P}(j, t)=\left\{\begin{array}{l}
P_{0}(j, t)(1+\rho)^{1 / 3}, \quad 0 \leq Q(j, t) \leq Q_{0}(j, t) \\
{\left[\mathrm{Q}(j, t)(1-\rho)^{1 / 3} / \alpha(j, t)\right]^{1 / \beta(j, t)}, \quad Q(j, t)>Q_{0}(j, t)}
\end{array}\right.
$$

As an example, Fig. 5(b) shows a plotting of the comparison of water price-demand functions under different scenarios of efficiency improvement for user I2 in May. Accordingly, the modified net benefits function for MI use can be derived as:

$$
\begin{aligned}
& N B_{j t}=\int_{0}^{Q(j, t)} \tilde{P}(j, t) d Q(j, t)-Q(j, t) w c(j, t) \\
& =\int_{Q_{0}(j, t)}^{Q(j, t)}\left[\mathrm{Q}(j, t)(1-\rho)^{1 / 3} / \alpha(j, t)\right]^{1 / \beta(j, t)} d Q(j, t)+\mathrm{P}_{0}(j, t)(1+\rho)^{1 / 3} \mathrm{Q}_{0}(j, t)-Q(j, t) w c(j, t)(1+\rho) \\
& =\left({ }^{1-\rho)^{1 / 3}} / \alpha(j, t)^{1 / \beta(j, t)} \frac{1}{1+1 / \beta(j, t)}\left[Q(j, t)^{1+1 / \beta(j, t)}-Q_{0}(j, t)^{1+1 / \beta(j, t)}\right]+\mathrm{P}_{0}(j, t)(1+\rho)^{1 / 3} \mathrm{Q}_{0}(j, t)\right. \\
& -Q(j, t) w c(j, t)(1+\rho), \quad \forall j \in M I
\end{aligned}
$$

When the net benefits functions with efficiency improvement are applied to the model, new allocation schemes and net benefits results can be obtained. The total net benefits will witness a further increase compared to the results with original net benefits functions, as shown in Fig. 6. In terms of the total net benefits for each stakeholder after cooperative reallocation, its pattern is quite similar to the results shown in Fig. 4. This outcome indicates that more net benefits can be produced and shared by stakeholders. 
(a)

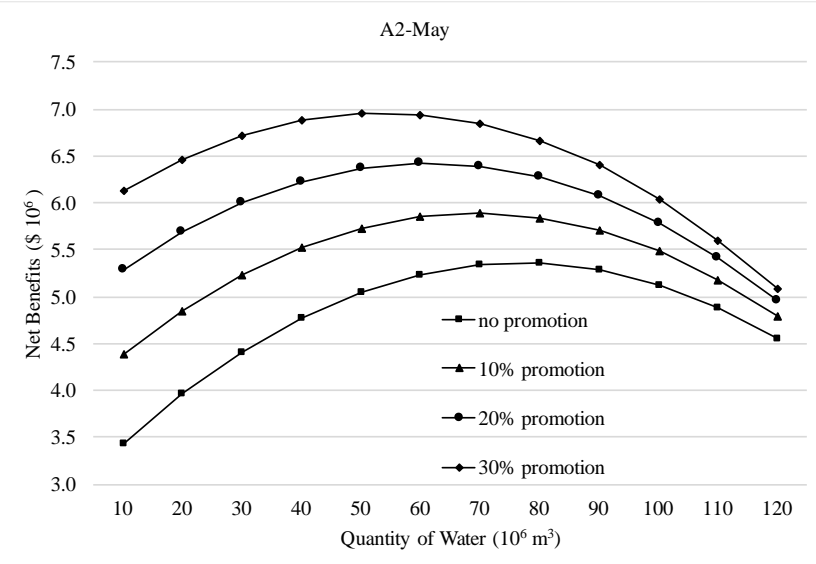

(b)

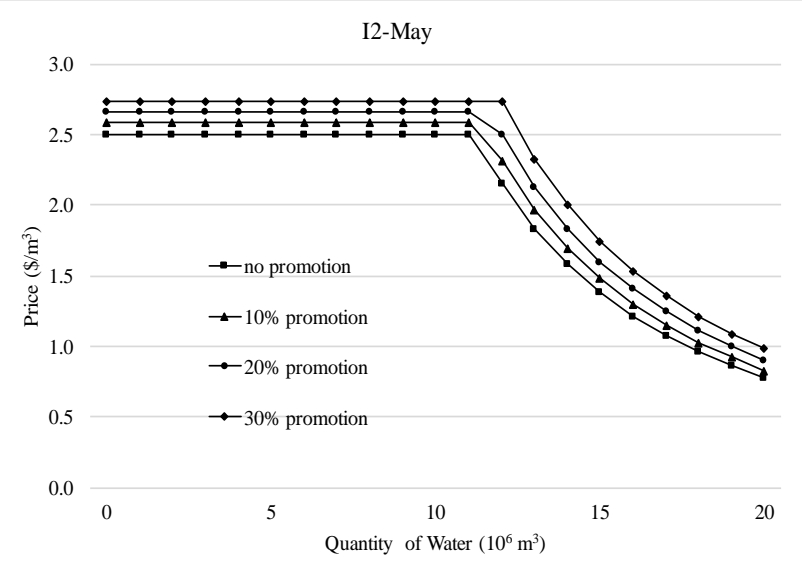

Fig. 5 (a) A comparison of net benefits functions under different scenarios of efficiency promotion for user A2 in May, and (b) a comparison of water price-demand functions under differenct scenarios of efficiency promotion for user I2 in May

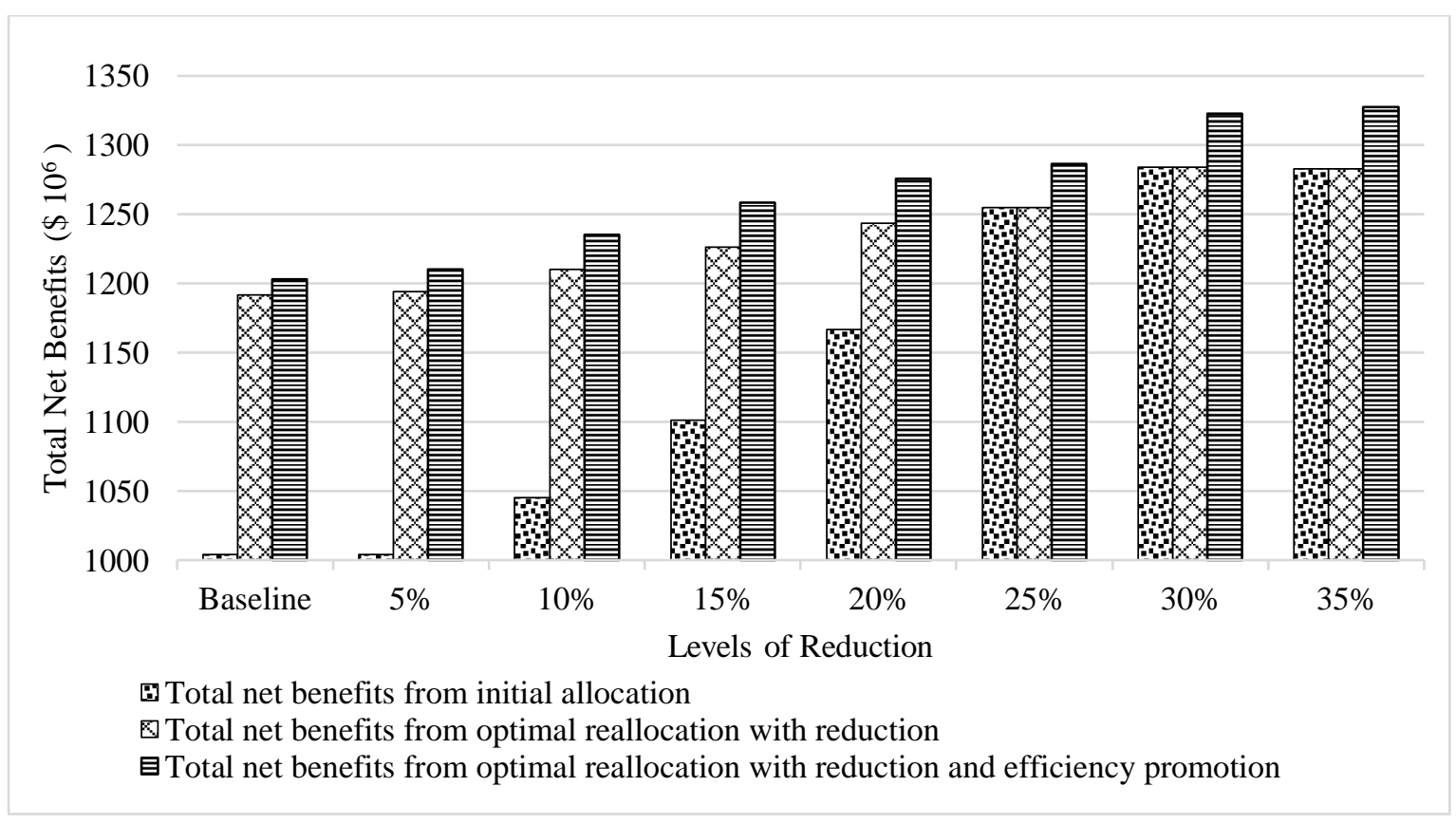

Fig. 6 Total net benefits from allocation under different scenarios in which different levels of reduction and efficiency promotion are considered and initial allocation is obtained from the PMMNF method

\section{Conclusions}

A water demand management plan is specified and incorporated into the Cooperative Water Allocation Model (CWAM) to investigate its impact on water users. The results demonstrate several advantages of a water demand management plan. Firstly, more aggregated net benefits for the grand coalition can be yielded through water transfer from less productive users to more productive users and cooperation among water users. Secondly, every stakeholder is able to gain more net benefits by means of a modified cooperative game to fairly 
allocate the additional net benefits, which provides motivation for water users to carry out a demand management plan. Finally, water demand management can play an important role in alleviating water stress facing humanity in the near future, and prevent more water conflicts from happening. It can thus be of great assistance in some arid and semi-arid regions, especially areas with low water productivity.

Acknowledgement The authors would like to thank the anonymous referees and the Associate Editor for providing helpful comments that enhanced the quality of this paper. The authors would also like to thank the Natural Sciences and Engineering Research Council (NSERC) of Canada for furnishing research funding. The first author would like to express his gratitude to the China Scholarship Council for providing financial support (No. 201206710003).

\section{References}

Alaya AB, Souissi A, Tarhouni J, Ncib K (2003) Optimization of Nebhana reservoir water allocation by stochastic dynamic programming. Water Resour Manag 17(4): 259-272

Ahmed JA, Sarma AK (2005) Genetic algorithm for optimal operating policy of a multipurpose reservoir. Water Resour Manag 19(2): 145-161

Araral E, Wang Y (2013) Water demand management: Review of literature and comparison in South-East Asia. Int J Water Resour Dev 29(3): 434-450

Brooks DB (2006) An operational definition of water demand management. Int J Water Resour Dev 22(4): 521-528

Cai X, McKinney DC, Lasdon LS (2001) Solving nonlinear water management models using a combined genetic algorithm and linear programming approach. Adv Water Resour 24(6): 667-676

Cai X, McKinney DC, Lasdon LS (2003) Integrated hydrologic-agronomic-economic model for river basin management. J Water Resour Plan Manag 129(1): 4-17

Christian-Smith J, Cooley H, Gleick PH (2012) Potential water savings associated with agricultural water efficiency improvements: a case study of California, USA. Water Policy 14(2): 194-213

FAO Statistical Yearbook (2013) World Food and Agriculture. Food and Agriculture Organization of the United Nations. URL: http://www.fao.org/docrep/018/i3107e/i3107e00.htm. Accessed 17 March 2015

GAMS Development Corporation (2005) GAMS-The solver manuals: OQNLP and MSNLP. Washington DC

Gleick PH (2003a) Global freshwater resources: soft-path solutions for the 21st century. Science 302(5650): 1524-1528

Gleick PH (2003b) Water use. Ann Rev Environ Resour 28(1): 275-314

Gleick PH, Christian-Smith J, Cooley H (2011) Water-use efficiency and productivity: rethinking the basin approach. Water Int 36(7): 784-798

Gleick PH, Heberger M (2014) Water conflict chronology. In: The World's Water volume 8: The biennial report on freshwater resources. Island Press/Center for Resource Economics, Washington DC, pp 173-219

Hipel KW, Fang L, Wang L (2013) Fair water resources allocation with application to the South Saskatchewan River basin. Can Water Resour J 38(1): 47-60

Huang WC, Yuan LC, Lee CM (2002) Linking genetic algorithms with stochastic dynamic programming to the long-term operation of a multireservoir system. Water Resour Res 38(12): 1304. doi: 10.1029/2001WR001122

Jacobs JM, Vogel RM (1998) Optimal allocation of water withdrawals in a river basin. J Water Resour Plan Manag 124(6): $357-$ 363

Kampragou E, Lekkas DF, Assimacopoulos D (2011) Water demand management: implementation principles and indicative case studies. Water Environ J 25(4): 466-476

Kilgour DM, Okada N, Nishikori A (1988) Load control regulation of water pollution: An analysis using game theory. J Environ Manag 27(2): 179-194

Kilic M, Anac S (2010) Multi-objective planning model for large scale irrigation systems: method and application. Water Resour Manag 24(12): 3173-3194

Kindler J (2010) Water demand management. In: A review of selected hydrology topics to support bank operations, HEF technical report 1, World Bank. Washington DC, pp 35-49

Kucukmehmetoglu M, Guldmann JM (2010) Multiobjective allocation of transboundary water resources: case of the Euphrates and Tigris. J Water Resour Plan Manag 136(1): 95-105 
Lejano RP, Davos CA (1995) Cost allocation of multiagency water resource projects: Game-theoretic approaches and case study. Water Resour Res 31(5): 1387-1393. doi:10.1029/95WR00322

Li YP, Huang GH, Huang YF, Zhou HD (2009) A multistage fuzzy-stochastic programming model for supporting sustainable waterresources allocation and management. Environ Model Softw 24(7): 786-797

Luo B, Maqsood I, Huang GH (2007) Planning water resources systems with interval stochastic dynamic programming. Water Resour Manag 21(6): 997-1014

Madani K (2010) Game theory and water resources. J Hydrol 381(3): 225-238

Madani K, Hipel KW (2011) Non-cooperative stability definitions for strategic analysis of generic water resources conflicts. Water Resour Manag 25(8): 1949-1977

Nicklow J, Reed P, Savic D, Dessalegne T, Harrell L, Chan-Hilton A, Karamouz M, Minsker B, Ostfeld A, Singh A, Zechman E, ASCE Task Committee on Evolutionary Computation in Environmental and Water Resources Engineering (2010) State of the art for genetic algorithms and beyond in water resources planning and management. J Water Resour Plan Manag 136(4): 412432

Okada N, Mikami Y (1992) A game-theoretic approach to acid rain abatement: conflict analysis of environmental load allocation. J Am Water Resour Assoc 28(1): 155-162

Owen G (1995) Game Theory, third ed. Academic Press, New York

Sahin, O, Stewart, RA, Helfer, F (2015) Bridging the water supply-demand gap in Australia: Coupling water demand efficiency with rain-independent desalination supply. Water Resour Manag 29(2): 253-272

Savenije HH, Van Der Zaag P (2002) Water as an economic good and demand management paradigms with pitfalls. Water Int 27(1): 98-104

Sechi GM, Zucca R, Zuddas P (2013) Water costs allocation in complex systems using a cooperative game theory approach. Water Resour Manag 27(6): 1781-1796

Shapley LS (1953) A value for n-person games. In: Kuhn HW, Tucker AW (eds) Contributions to the theory of games, vol II. Annals of Mathematics Studies, vol 28. Princeton University Press, Princeton, pp 307-317

Speed R, Li Y, Le Quesne T, Pegram G, Zhiwei Z (2013) Basin water allocation planning: principles, procedures and approaches for basin allocation planning. United Nations Educational, Scientific and Cultural Organization (UNESCO), Paris

Takama N, Kuriyama T, Shiroko K, Umeda T (1981) On the formulation of optimal water allocation problem by linear programming. Comput Chem Eng 5(2): 119-121

Tate DM (1989) Water demand management in Canada: A review and assessment. Can Water Resour J 14(4): 71-82

Tisdell JG, Harrison SR (1992) Estimating an optimal distribution of water entitlements. Water Resour Res 28(12): 3111-3117. doi:10.1029/92WR01795

Tortajada C, Joshi YK (2013) Water demand management in Singapore: involving the public. Water Resour Manag 27(8): 27292746

Wang L, Fang L, Hipel KW (2003) Water resources allocation: a cooperative game theoretic approach. J Environ Inf 2(2): 11-22

Wang L, Fang L, Hipel KW (2007) Mathematical programming approaches for modeling water rights allocation. J Water Resour Plan Manag 133(1): 50-59

Wang L, Fang L, Hipel KW (2008) Basin-wide cooperative water resources allocation. Eur J Oper Res 190(3): 798-817

Xiao Y, Hipel KW, Fang L (2015) Towards more productive water allocation with water demand management. Proc 2015 IEEE Int Conf Syst, Man Cybern (SMC), Hong Kong, October 9 to 12, 2015, pp. 606-611

Yang YCE, Zhao J, Cai X (2011) Decentralized optimization method for water allocation management in the Yellow River basin. J Water Resour Plan Manag 138(4): 313-325

Young HP, Okada N, Hashimoto T (1982) Cost allocation in water resources development. Water Resour Res 18(3): 463-475. doi:10.1029/WR018i003p00463

Ziolkowska, JR (2015) Is Desalination Affordable?-Regional Cost and Price Analysis. Water Resour Manag 29(5): 1385-1397 